\title{
PEDESTRIAN QUALITY OF SERVICE AT UNPROTECTED MID-BLOCK CROSSWALK LOCATIONS UNDER MIXED TRAFFIC CONDITIONS: TOWARDS QUANTITATIVE APPROACH
}

\author{
Bhadradri Raghuram Kadali, Perumal Vedagiri \\ Dept of Civil Engineering, Indian Institute of Technology Bombay, India
}

Submitted 7 November 2014; resubmitted 12 April 2015; accepted 22 July 2015;

published online 04 May 2016

\begin{abstract}
Safety, comfort, convenience and minimal delay are essential for pedestrians at mid-block crosswalk locations. Therefore, it is necessary to evaluate the quality of crosswalk with these qualitative parameters. In this study, qualitative parameters such as safety, crossing opportunities (available time gaps) and delay index values are considered as a single measure of effectiveness as a Pedestrian Crossing Index (PCI) for evaluation of Quality Of Service (QOS) at unprotected mid-block crosswalk locations under mixed traffic conditions. Further, the study is aimed at identifying the factors contributing to the pedestrian QOS. In order to achieve these objectives, field surveys were conducted at eight different unprotected mid-block crosswalk locations to collect pedestrian individual (age and gender), behavioural, traffic and roadway characteristics. An ordered probit model has been developed to find out the significant factors contributing to the pedestrian QOS by taking QOS as the dependent variable and other collected variables as independent variables. The model results show that several factors have significant effect on pedestrian QOS and out of these, factors such as rolling behaviour, speed change behaviour of pedestrian, vehicle speed, number of lanes and number of vehicle encountered were identified as the primary factors affecting pedestrian QOS at unprotected midblock crosswalk locations. The developed model may be useful for design and evaluation of the existing pedestrian QOS at unprotected mid-block crosswalk locations under mixed traffic conditions.
\end{abstract}

Keywords: pedestrian; quality of service; safety; mid-block; behaviour; gap; ordered probit.

\section{Introduction}

Pedestrians are vulnerable road users and mobility as well as safety of the pedestrian at unprotected mid-block crosswalk locations is still vague under mixed traffic conditions. The unprotected mid-block crosswalks are locations with median opening to allow pedestrian to cross the road, to access the adjacent land-use facilities, such as malls, shopping complexes, hospitals, residential apartment, bus stops, etc. These crosswalks are away from intersection locations and most of these are unsignalized, with or without marking or signboards to control motorized vehicle movement. Such crosswalks are common in cities of developing countries like India, where the pedestrian density is quite high necessitating the need for such crossing facilities. Due to low quality of pedestrian facilities, pedestrian-vehicle crashes are also higher at such crosswalks (Ponnaluri 2012). Studies have shown that high population growth rates in developing countries increases the pedestrian density and it needs a special emphasis on pedestrian safety as well as design of new facilities (Lasmini, Indriastuti 2010). Thus, there is a significant impact of pedestrian-vehicle interaction on pedestrian safety as well as mobility at these crosswalks. The quality of the pedestrian service is degrading over the years because of the increase in private vehicles and also traffic operations as well as roadway designs favouring the private vehicle users in particularly under mixed traffic conditions. In general, the quality of operations of transportation facilities is assessed by Level Of Service (LOS). Such a LOS measure helps in evaluation of the existing facilities as well as design of new transportation facilities.

At unprotected mid-block crosswalk locations, motorists and pedestrians often have to deal with complex situations and pedestrians need to search for suitable vehicular gaps to cross the road. Generally, pedestrian rarely follows the restricted path or the usual speed $(1.2 \mathrm{~m} / \mathrm{s})$ at crosswalk locations. They adjust their road crossing speed with available approaching vehicular

Corresponding author: Bhadradri Raghuram Kadali

E-mails: raghukadali@civil.iitb.ac.in; raghukadali@gmail.com 
gaps, speed as well as type of vehicle. In such situations, the quality of crosswalk may depend on the available vehicular gaps as well as pedestrian safety with vehicular traffic. In India, there are several unprotected midblock crosswalks, which may not guarantee the pedestrian safety and people may use such crosswalks due to their urgency of daily activities. Further, studies have shown that due to limited availability of funding the quality of pedestrian facilities in developing countries is quite different when compared to the developed countries (Leather et al. 2011). Due to this, pedestrian related collisions are increasing at the unprotected mid-block crosswalk locations under mixed traffic condition. Earlier studies have reported that $60 \%$ fatalities are related to pedestrian in urban areas and out of these $85 \%$ occur at mid-block crosswalk locations (Mohan et al. 2009). Hence, evaluating such pedestrian facilities in developing countries are more important.

Usually, the quality of sidewalk evaluation is carried out with pedestrian flow characteristics such as pedestrian flow, density and speed. However, such an evaluation is suitable for the high pedestrian flow condition, which is useful for congestion and evacuation scenarios. In general, the quality of signalized crosswalk was evaluated with pedestrian delay. However, compliant behaviour of pedestrians may result in pedestrians not searching for the vehicular gaps at signalized crosswalk locations. In contrast, at unprotected (unsignalized) mid-block crosswalk locations, pedestrian may look for vehicular gaps and may exhibit wide variation in their behaviour. Hence, the quality of uncontrolled mid-block crosswalk location may depend on the vehicular flow conditions with available vehicular time gaps, pedestrian safety and delay. Evaluation of such unprotected mid-block crosswalk locations with new measure of effectiveness such as available vehicular time gaps and safety along with delay as a common index like Pedestrian Crossing Index (PCI) is an important under mixed traffic condition. In this framework, the purpose of this study is to propose a new method to evaluate the pedestrian QOS in terms of PCI at unprotected mid-block crosswalk locations under mixed traffic condition and identify the contributing factors on QOS. The organization of this research paper is as follows: Section 1 describes the background about the pedestrian LOS models. In section 2, an overview of the site characteristics and the data collection process is presented. Section 3 presents the pedestrian QOS model developed in the study. Section 4 describes the model results and discussion. The conclusions are summarized paper.

\section{Literature Review}

Several studies have been carried out to evaluate the pedestrian QOS by quantitative and qualitative methods. Researchers have shown the importance of qualitative parameters in pedestrian LOS (Sarkar 1993; Khisty 1994). Researchers have considered pedestrian delay and space as the performance measures for pedestrian
LOS at signalized crosswalks (Highway Capacity Manual 2010; Petritsch et al. 2005; Bian et al. 2013). In some studies, pedestrian speed and pedestrian compliance rate were used to evaluate the pedestrian LOS (Milazzo et al. 1999). Further, studies have shown the importance of qualitative factors to evaluate pedestrian LOS at crosswalk locations (Nagraj, Vedagiri 2013; Jensen 2013). However, these methodologies are limited to the signalized crosswalks and cannot be applied to other crosswalk locations such as unprotected mid-block crosswalk locations. Moreover, studies have explored the importance of pedestrian gap acceptance and safety while crossing at unprotected mid-block crosswalks (Sun et al. 2003; Yannis et al. 2013; Kadali, Vedagiri 2013). Further, none of these studies has been associated with pedestrian QOS. Researchers have also shown the importance of relationship between pedestrian safety by conflict method and actual field collected data (Hauer, Gårder 1986).

Studies have been carried at signalized mid-block crosswalk locations to measure the pedestrian QOS (Chu, Baltes 2003). In early studies, the main contributing performance factors such as pedestrian delay, safety and crossing opportunities were considered in the first stage by theoretical studies and field surveys. In second stage contributing factors were derived for the pedestrian QOS and stepwise regression model was developed at signalized mid-block crosswalk locations (Baltes, Chu 2002). However, the crossing opportunities are quite easy at signalized mid-block crosswalks. The pedestrian safety is also high because of less interaction with vehicular traffic when compared to the unprotected midblock crosswalk location. Pedestrians have to search for adequate vehicular gaps to cross the road at unprotected mid-block crosswalk locations. Therefore, pedestrians may wait until they get suitable vehicular gap. However, they may use behavioural characteristics (increase in speed, rolling behaviour, etc.) at such situations to cross the road with a minimum gap as well as less delay. In this situation, pedestrian safety will be reduced because of the more interaction with the vehicular flow. Therefore, pedestrian QOS is complex at unprotected midblock crosswalk location as compared to the signalized mid-block crosswalk locations. However, these studies do not address the pedestrian QOS by quantification of pedestrian safety, gap opportunities and delay at unprotected mid-block crosswalk facilities under mixed traffic condition. In this view, the present study has considered pedestrian delay, vehicular gaps and pedestrian safety as a combined performance measure in terms of PCI for the evaluation of pedestrian QOS. Further, the QOS model was developed to identify the important contributing factors at unprotected mid-block crosswalk locations under mixed traffic condition.

\section{Methodology}

In this study, performance measures such as vehicular gap, pedestrian delay and pedestrian safety were collected from the video graphic technique. Along with these performances measures pedestrian individual, behav- 
ioural and traffic characteristics were also captured. The collected data indicates that how pedestrians are using behavioural characteristics at different roadway characteristics, vehicular flow conditions, and land-use conditions. The pedestrian crossing preference of safety, delay and crossing opportunities of these selected unprotected mid-block crosswalk locations were also collected by stated preference survey carried out simultaneously with the video survey.

\subsection{Site Selection}

For the study, eight sites were selected in Mumbai city, India with different roadway, pedestrian flow characteristics and land use type, as shown in Fig. 1. These selected sites have a variety of median widths and median open width, traffic volumes, vehicle speeds and pedestrian behavioural characteristics with range of available gaps. This variety in roadway types was intended for including different conditions in the study and developing a generic model for pedestrian QOS. The preliminary survey was conducted before conducting an actual video survey in order to get the data such as the number of lanes, crosswalk length and median width. The selected sites are summarized in Table 1 with detailed roadway and operational characteristics.

\subsection{Data Collection}

The video survey was conducted at each location for a period of 2 to 3 hours and 2 to 3 video cameras were placed at the site depending upon the site location. One video camera was placed at the vantage point in order to collect pedestrian speed and vehicular speeds. The second video was placed at close to the crosswalk locations in order to capture the behaviour of the pedestrian.
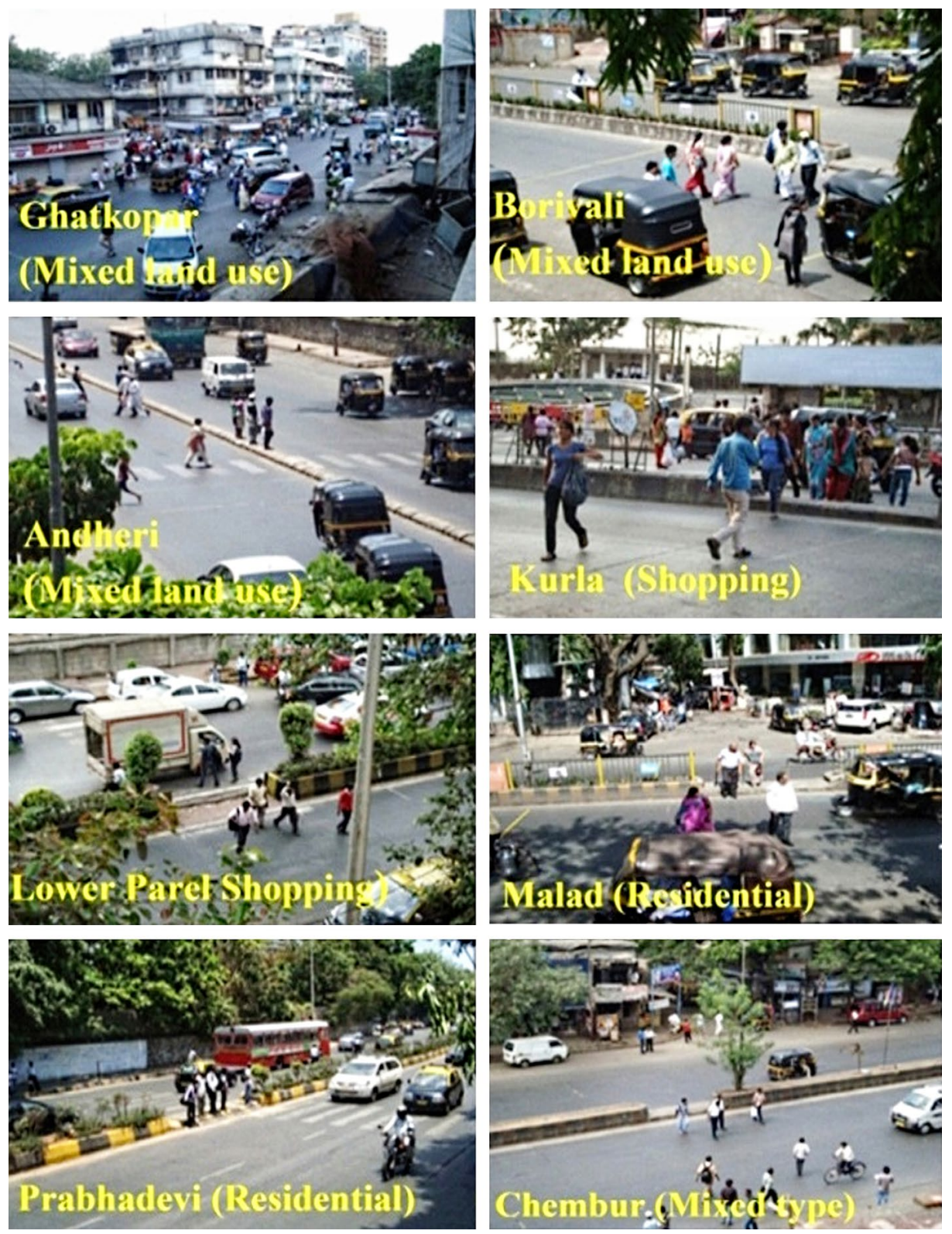

Fig. 1. The selected unprotected mid-block crosswalk locations 
Table 1 . The roadway and operational characteristics of the selected crosswalks

\begin{tabular}{|c|l|c|c|c|c|c|c|}
\hline $\begin{array}{c}\text { Site } \\
\text { No. }\end{array}$ & $\begin{array}{c}\text { Location } \\
\text { name }\end{array}$ & $\begin{array}{c}\text { Land use } \\
\text { type }\end{array}$ & $\begin{array}{c}\text { Total number } \\
\text { of lanes }\end{array}$ & $\begin{array}{c}\text { Width of } \\
\text { median }[\mathrm{m}]\end{array}$ & $\begin{array}{c}\text { Median open } \\
\text { width }[\mathrm{m}]\end{array}$ & $\begin{array}{c}\text { Pedestrian average } \\
\text { speed }[\mathrm{m} / \mathrm{s}]\end{array}$ & $\begin{array}{c}\text { Average motor } \\
\text { vehicle speed }[\mathrm{km} / \mathrm{h}]\end{array}$ \\
\hline 1 & Ghatkopar & mixed type & 2 & 0 & not applicable & 1.12 & 16.80 \\
\hline 2 & Borivali & mixed type & 4 & 0.7 & 3 & 1.35 & 23.54 \\
\hline 3 & $\begin{array}{l}\text { Andheri } \\
\text { Parsiwada }\end{array}$ & mixed type & 4 & 0.45 m curb & not applicable & 1.45 & 26.95 \\
\hline 4 & Kurla & shopping & 4 & 1.0 & 3 & 1.17 & 22.88 \\
\hline 5 & Lower Parel & shopping & 4 & 1.0 & 3 & 1.21 & 23.84 \\
\hline 6 & Malad & residential & 4 & 0.7 & 3.5 & 1.16 & 31.41 \\
\hline 7 & Prabhadevi & residential & 6 & 1.25 & 5 & 1.06 & 39.96 \\
\hline 8 & Chembur & mixed type & 6 & 1.0 & 3.5 & 1.38 & 37.76 \\
\hline
\end{tabular}

\subsection{Data Extraction}

The video was captured and frame-by-frame data was extracted with the help of AVS video editor software. At each selected location data such as vehicular characteristics (vehicle type and speed) and pedestrian behavioural characteristics were extracted by clicking a step forward option of the software at an accuracy of 1 in $30 \mathrm{~s}(0.033 \mathrm{~s})$. The pedestrian individual characteristics comprising of gender and age were collected based on visual appearance and given in Table 2.

\subsubsection{Traffic Characteristics}

The accepted vehicular gap data of each pedestrian was extracted corresponding to the pedestrian crossing path while pedestrian crosses the road. Vehicle speeds were extracted by reference known length $(20 \mathrm{~m})$, which was marked on the ground. Pedestrian speeds were also extracted based on the crosswalk length. Pedestrian delay was calculated as the sum of waiting time at the curb as well as the median location while crossing from the curb-to-curb location. Pedestrian safety margin can be defined as the time difference between accepted vehicular time gap and pedestrian actual crossing time (based on the field condition and pedestrian behaviour) (Lobjois, Cavallo 2009). The pedestrian safety margin was extracted at each stage of crossing and the final value is noted as the least value of all the extracted safety margin of each crossing pedestrian in curb-to-curb crossing.

\subsubsection{Pedestrian Behavioural Characteristics}

The pedestrians' behavioural data such as rolling and pedestrian speed change behaviour, pedestrian platoon behaviour, the frequency of attempt and usage of cell phone during crossing were extracted from the video. In this study, the pedestrian rolling behaviour is one of the important parameters influencing pedestrian behaviour. Pedestrians are rolling over the small vehicular gaps to accept minimal vehicular gaps for reducing overall delay, which is characterized as a rolling behaviour (Brewer et al. 2006; Kadali, Vedagiri 2013). The collected data and their statistical observations are summarized in Table 2.
From the previous studies, the pedestrian behavioural characteristics have significant effect on pedestrian safety at crosswalks (Hamed 2001; Ishaque, Noland 2008; Faria et al. 2010; Havard, Willis 2012; Kadali, Vedagiri 2013; Jain et al. 2014). Further, the present study considered pedestrian safety is an important measure of effectiveness to evaluate the QOS at unprotected midblock crosswalk locations. Therefore, the pedestrian behavioural characteristics have significant effect on QOS.

The increase in population growth in developing countries increases the number of pedestrian trips and it further leads them to access the crosswalks within short distance (less than $50 \mathrm{~m}$ ) for crossing the road (Leather et al. 2011). Researchers also found that there is a significant difference observed between pedestrian crashes in developed countries when compared with developing countries and they concluded that behaviour of pedestrian significantly influences their crossing behaviour in densely populated cities (Tulu et al. 2013). The increase in pedestrian crosswalks increases the aggressive behaviour of driver and reduces their yielding to the pedestrians when they are waiting at curb or median in developing countries. Due to this, the pedestrian use different behavioural characteristics to cross the road to reduce the waiting time (Kadali, Vedagiri 2013). Further, the change in pedestrian behaviour by different road crossing patterns, vehicle characteristics and driver behaviour have significant contribution in pedestrian safety, which is an important parameter in pedestrian QOS (Chu, Baltes 2003).

Studies have also found the effect of driver yielding behaviour on pedestrian safety (Gårder 2004). Researchers have investigated the effect of crosswalk marking on pedestrian behaviour as well as driver (Knoblauch et al. 2001). Researchers have also shown that the bus stops, number of traffic lanes, pedestrian as well vehicle volumes have significant contribution on pedestrian safety at mid-block crosswalks (Diogenes, Lindau 2010). Moreover, studies indicate that the change in pedestrian behavioural characteristics have significant effect on pedestrian safety at crosswalks (Hamed 2001; Ishaque, Noland 2008; Faria et al. 2010; Havard, Willis 2012; Kadali, Vedagiri 2013; Jain et al. 2014). Based on these available literature the present study identified significant 
Table 2. Descriptive statistics of selected variables

\begin{tabular}{|c|c|c|c|c|}
\hline \multicolumn{2}{|c|}{ Variable } & $\begin{array}{c}\% \text { of } \\
\text { value } \\
\end{array}$ & Mean & $\begin{array}{l}\text { Standard } \\
\text { deviation }\end{array}$ \\
\hline \multicolumn{2}{|c|}{ Pedestrian safety margin $[\mathrm{s}]$} & - & 2.94 & 2.39 \\
\hline \multicolumn{2}{|l|}{ Pedestrian delay [s] } & - & 19.5 & 22.71 \\
\hline \multicolumn{2}{|c|}{ Pedestrian speed $[\mathrm{m} / \mathrm{s}]$} & - & 1.23 & 0.36 \\
\hline \multicolumn{2}{|c|}{ Vehicular gap size [s] } & - & 5.87 & 2.81 \\
\hline \multicolumn{2}{|c|}{ Vehicle speed $[\mathrm{km} / \mathrm{h}]$} & - & 25.4 & 9.32 \\
\hline \multicolumn{2}{|l|}{ Stage of crossing } & - & 1.44 & 0.5 \\
\hline \multicolumn{2}{|c|}{ Frequency disturbance } & - & 0.364 & 0.84 \\
\hline \multicolumn{2}{|c|}{ Frequency of an attempt } & - & 1.8 & 1.12 \\
\hline \multirow{2}{*}{$\begin{array}{l}\text { Pedestrian } \\
\text { gender }\end{array}$} & male $=1$ & 32.2 & \multirow{2}{*}{0.685} & \multirow{2}{*}{0.467} \\
\hline & female $=0$ & 67.8 & & \\
\hline \multirow{4}{*}{ Pedestrian age } & child = 1 & 2.1 & \multirow{4}{*}{2.72} & \multirow{4}{*}{0.69} \\
\hline & young $=2$ & 35.7 & & \\
\hline & middle $=3$ & 50.6 & & \\
\hline & elders $=4$ & 11.6 & & \\
\hline \multirow{3}{*}{$\begin{array}{l}\text { Pedestrian } \\
\text { platoon size }\end{array}$} & single $=1$ & 46.4 & \multirow{3}{*}{1.84} & \multirow{3}{*}{0.864} \\
\hline & two $=2$ & 22.8 & & \\
\hline & three $=3$ & 30.8 & & \\
\hline \multirow{2}{*}{$\begin{array}{l}\text { Pedestrian speed } \\
\text { change behaviour }\end{array}$} & no $=1$ & 78.2 & \multirow{2}{*}{1.22} & \multirow{2}{*}{0.41} \\
\hline & yes $=2$ & 21.8 & & \\
\hline \multirow{2}{*}{$\begin{array}{l}\text { Pedestrian usage } \\
\text { of cell phone }\end{array}$} & no $=1$ & 94.7 & \multirow{2}{*}{1.05} & \multirow{2}{*}{0.22} \\
\hline & yes $=2$ & 5.3 & & \\
\hline \multirow{2}{*}{$\begin{array}{l}\text { Pedestrian } \\
\text { rolling behaviour } \\
\text { condition }\end{array}$} & no $=1$ & 72.8 & & \\
\hline & yes $=2$ & 27.2 & 1.27 & 0.44 \\
\hline Concentration & $\begin{array}{l}\text { not } \\
\text { applicable }=0\end{array}$ & 3.4 & & \\
\hline on vehicular gaps & no $=1$ & 5.0 & 1.88 & 0.42 \\
\hline & yes $=2$ & 91.6 & & \\
\hline & \begin{tabular}{|l|} 
two \\
wheeler $=2$ \\
\end{tabular} & 21.9 & & \\
\hline Type of vehicle & $\begin{array}{l}\text { three } \\
\text { wheeler }=3\end{array}$ & 26.6 & 3.35 & 0.89 \\
\hline & car $=4$ & 45.5 & & \\
\hline & heavy $=5$ & 6 & & \\
\hline Driver yield & $\begin{array}{l}\text { not } \\
\text { applicable }=0\end{array}$ & 35.8 & & \\
\hline behaviour & no $=1$ & 22.4 & 1.06 & 0.87 \\
\hline & yes $=2$ & 41.8 & & \\
\hline Accepted lag or & $\operatorname{lag}=1$ & 11.6 & 180 & 056 \\
\hline gap & gap $=2$ & 88.4 & 1.88 & 0.56 \\
\hline & near $=1$ & 49.4 & 1.54 & 0.56 \\
\hline 1ype of gap & far $=2$ & 50.6 & 1.54 & 0.56 \\
\hline Zebra marking & no $=1$ & 62.5 & 138 & 0 \\
\hline condition & yes $=2$ & 37.5 & 1.38 & 0. \\
\hline Number of lanes & & - & 4.43 & 1.31 \\
\hline Width of median & & - & 0.83 & 0.39 \\
\hline Number of vehicle & s encountered & - & 13 & 17 \\
\hline $\begin{array}{l}\text { Land use type (mi } \\
\text { residential = 2; sh }\end{array}$ & $\begin{array}{l}\text { xed type }=1 \\
\text { opping }=3 \text { ) }\end{array}$ & - & 1.81 & 0.852 \\
\hline
\end{tabular}

contributors on pedestrian safety as rolling behaviour, speed change condition, vehicle speed, etc. Further, the present study considered pedestrian safety is an important measure of effectiveness to evaluate the QOS at unprotected mid-block crosswalk locations.

\subsection{Model Formulation}

The extracted video survey data was utilized for the formulation of the pedestrian QOS and identifying the contributing variables on pedestrian QOS. The pedestrian QOS was formulated based on PCI, which is derived from the performance measure of pedestrian safety, pedestrian accepted gap (crossing opportunities due to vehicular gaps) and pedestrian delay index values. Total 5216 data points with different behavioural characteristics of pedestrians' were used from six different locations for modelling and the data from two sites 'Andheri Parishwada as well as Malad' (720 data points) was used for validation of the developed model.

\subsubsection{Pedestrian Quality of Service}

In this study, pedestrian Quality Of Service (QOS) is derived from the PCI, which comprises of pedestrian safety, vehicular gaps and pedestrian delay index values. The safety margin values were used to define the criteria for Pedestrian Safety Index (PSI) values and it ranges from 1 to 6 . The cumulative graph of pedestrian safety margin was plotted. From the cumulative graph, 50th percentile was considered as the mean safety margin value $(2.36 \mathrm{~s})$, which is shown in Fig. 2. The 50th percentile $(2.36 \mathrm{~s})$ was selected as the breakpoint in the middle of the cumulative graph, which is middle of the safety index scale between 3 and 4 . The other index values were selected corresponding to the increasing and decreasing values from the 50th percentile break point value on yaxis. The safety index scale between 3 to 2 as well as 5 to 4 were selected by increase and decrease from 50th percentile break point a value by $25 \%$. Further, the scale such as 2 to 1 and 6 to 5 were selected by a value of $45 \%$ increase and decrease from 50th percentile break point (Harkey et al. 1998).

Further, pedestrian gap index can be derived from the pedestrian crossing opportunities by accepted vehicular gaps. The pedestrian gap index may represent the pedestrian comfort and convenience while crossing the road to some extent safety. The gap index values were derived by using cumulative graph method same as previous procedure (PSI). Moreover, pedestrian may experience a delay at middle of the road, at the curb as well as the median while crossing from curb to median and median to curb. So, the overall delay was considered to define the pedestrian delay index value. The delay index was derived by using cumulative graph method, which is same as that followed in the PSI procedure.

The stated preference survey was also conducted along with video graphic survey and this stated preference survey contains the ranks of safety, difficulty (available adequate gaps) and delay as pedestrian crossing preference while crossing the road. From the stated preference data (total 1200 responses from 8 locations), the 
pedestrians mean observed ranks are as follows: higher preference to safety next to difficulty (gap opportunities for crossing) and delay is given third rank. Based on the questionnaire survey it is observed that pedestrians gave more weightage to safety as well as comfort as compared to the delay. However, if the observed waiting time at selected locations increases drastically, then the perception of pedestrian may change and the weightage to pedestrian delay may be higher as compared to the vehicular gap as well as safety. However, such higher delay time was not observed in this study, if the waiting time increases drastically then perception of pedestrian needs to be studied at such selected locations. Further, the weights were calculated based on the rank order centroid method (Chang 2004) as shown in equation 1. From the ranked data, the weights were calculated such as 0.6 for safety, 0.28 for the gap index and 0.12 for delay. Further, PCI was calculated by multiplying weighted average values with PSI, gap index and delay index values.

The cumulative distribution of PCI values was drawn, which is shown in Fig. 3. Pedestrian QOS values such as QOS A, B, C, D, E and F were derived from the $\mathrm{PCI}$ values corresponding to the cumulative percentiles of 5, 25, 50, 75 and 95 respectively (Harkey et al. 1998). The ranges of PCI values with corresponding pedestrian QOS designations are shown in Table 3.

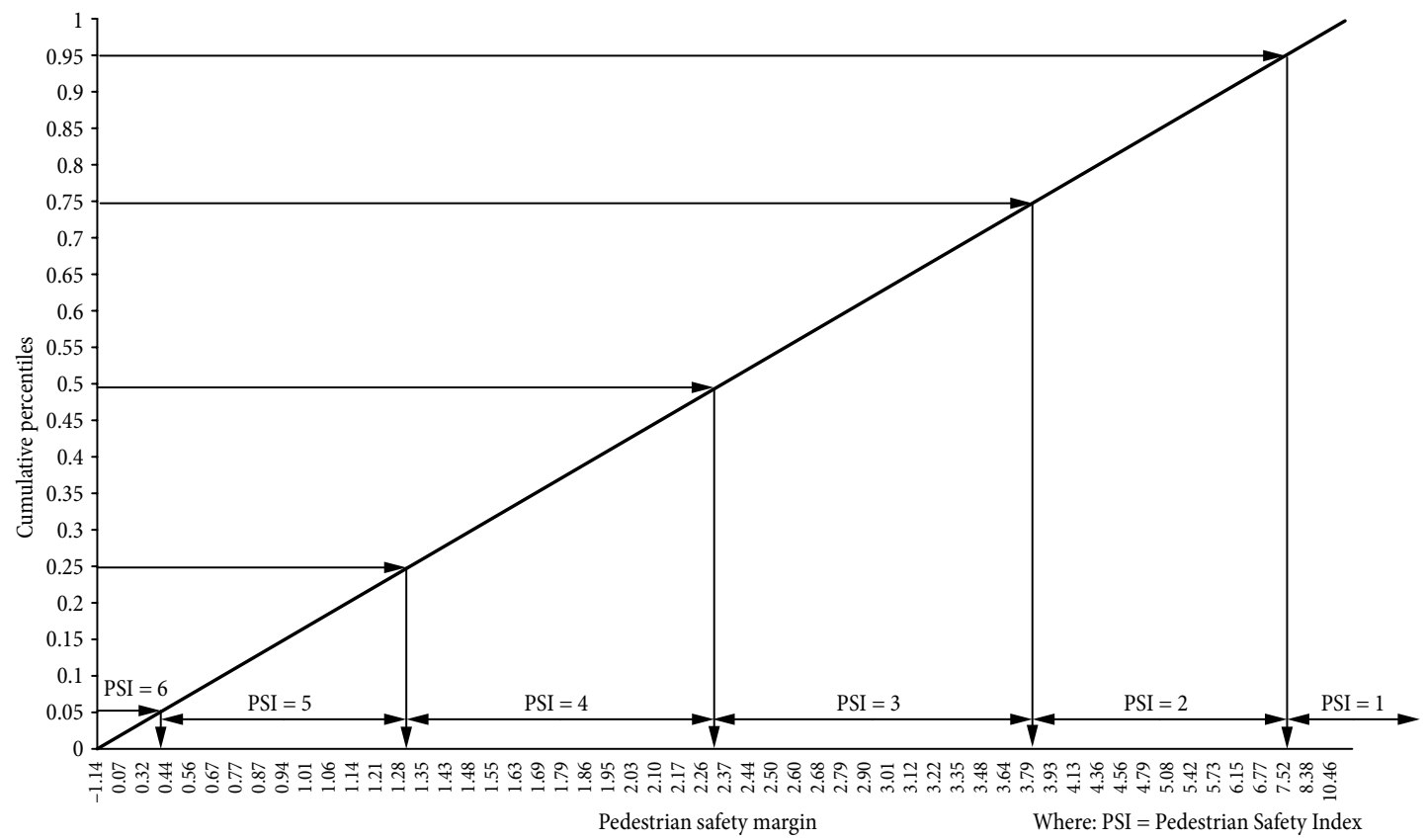

Fig. 2. Distribution of pedestrian safety margin used for PSI

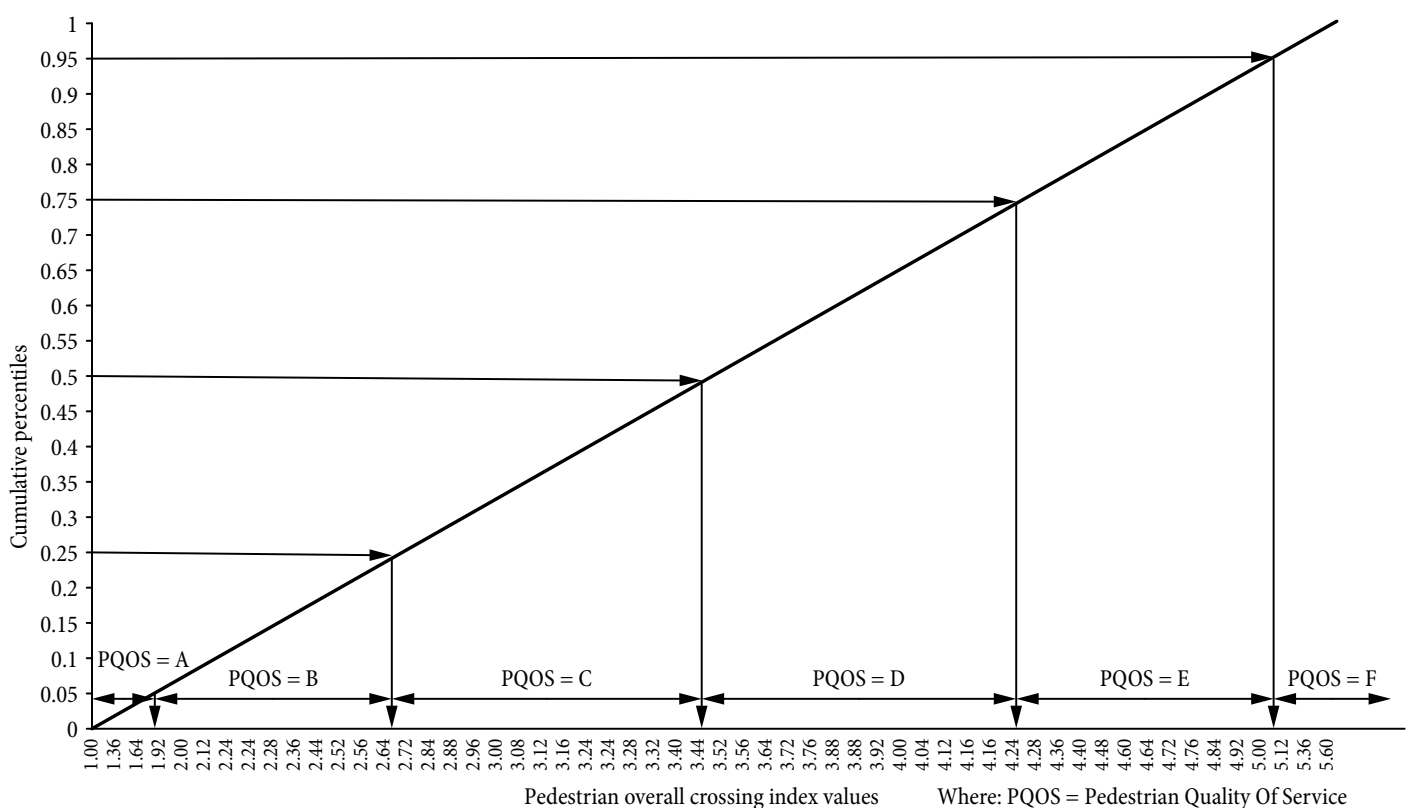

Fig. 3. Distribution of PCI used for pedestrian QOS 
Table 3. Pedestrian safety, gap, delay and crossing index values

\begin{tabular}{|c|c|c|c|c|c|c|c|}
\hline \multicolumn{2}{|c|}{ Pedestrian safety index } & \multicolumn{2}{c|}{ Pedestrian gap index } & \multicolumn{2}{c|}{ Pedestrian delay index } & \multicolumn{2}{c|}{ Pedestrian crossing index } \\
\hline $\begin{array}{c}\text { Safety index } \\
\text { values }\end{array}$ & $\begin{array}{c}\text { Safety } \\
\text { margin [s] }\end{array}$ & $\begin{array}{c}\text { Gap index } \\
\text { values }\end{array}$ & $\begin{array}{c}\text { Accepted vehicular } \\
\text { gaps [s] }\end{array}$ & $\begin{array}{c}\text { Delay index } \\
\text { values }\end{array}$ & Delay [s] & $\begin{array}{c}\text { Pedestrian } \\
\text { QOS }\end{array}$ & PCI range \\
\hline 1 & $\geq 7.64$ & 1 & $\geq 11.67$ & 1 & $\leq 0.8$ & $\mathrm{~A}$ & $\leq 1.88$ \\
\hline 2 & $3.86-7.63$ & 2 & $7.16-11.66$ & 2 & $0.81-4.25$ & $\mathrm{~B}$ & $1.89-1.72$ \\
\hline 3 & $2.37-3.85$ & 3 & $5.31-7.15$ & 3 & $4.26-12.16$ & $\mathrm{C}$ & $1.73-3.52$ \\
\hline 4 & $1.32-2.36$ & 4 & $3.88-5.30$ & 4 & $12.17-26.3$ & $\mathrm{D}$ & $3.53-4.28$ \\
\hline 5 & $0.41-1.31$ & 5 & $2.61-3.87$ & 5 & $26.31-63.81$ & $\mathrm{E}$ & $4.29-5.07$ \\
\hline 6 & $\leq 0.4$ & 6 & $\leq 2.6$ & 6 & $\geq 63.8$ & $\mathrm{~F}$ & $\geq 5.08$ \\
\hline
\end{tabular}

$$
\mathrm{W}_{i}=\left(\frac{1}{M}\right) \sum_{k=i}^{M} \frac{1}{n},
$$

where: $M$ is the number of ranks; $W_{i}$ is the weight for $i$-th rank.

\subsection{Pedestrian QOS Model}

For developing pedestrian QOS model, which is dependent variable more than one value (ordered as well as discrete data), ordered probability choice models prove to be the appropriate method. In addition, order probit models capture the qualitative difference between two levels. The simple linear regression and multinomial logit model does not infer the effect of ordering of the dependent variable. Simple regression model assumes differences between categories of the dependent variable to be equal (Khattak et al. 1993). So, the ordered probability model can allow for heterogeneity in the threshold parameters, in the descriptive variables (through random parameters), and in the decomposition of the residual variance (Greene, Hensher 2010; Washington et al. 2010). Hence, for this type of discrete and ordered nature of the data, an ordered probability approach is more suitable for modelling. The ordered probit model uses the following form:

$$
y_{i}^{*}=X_{i} \beta+\varepsilon_{i},
$$

where: $y_{i}^{*}$ is the depended variable, which is coded as $0,1,2,3,4,5$, which is a linear function of observed variables; $X$ is a vector of variables that determines the pedestrian QOS of mid-block unprotected crosswalk; $\beta$ is a vector of parameters to be estimated; $\varepsilon_{i}$ is a random error term (assumed to follow a standard normal distribution).

Let $y_{i}$ be the observed pedestrian QOS, which takes values from $\mathrm{A}$ to $\mathrm{F}$ ( $\mathrm{A}, \mathrm{B}, \mathrm{C}, \mathrm{D}, \mathrm{E}$ and $\mathrm{F}$ modified as 1 , $2,3,4,5$ and 6 respectively) as explained below follows:

$$
\begin{cases}y=1, & \text { if } y_{i}^{*} \leq 0 ; \\ y=2, & \text { if } 0<y_{i}^{*} \leq \mu_{1} ; \\ y=3, & \text { if } \mu_{1}<y_{i}^{*} \leq \mu_{2} ; \\ y=4, & \text { if } \mu_{2}<y_{i}^{*} \leq \mu_{3} ; \\ y=5, & \text { if } \mu_{3}<y_{i}^{*} \leq \mu_{4} ; \\ y=6, & \text { if } y_{i}^{*} \geq \mu_{5},\end{cases}
$$

where: $\mu_{0}=0$ and $\mu_{5}=+\infty$ and $\mu_{1}<\mu_{2}<\mu_{3}<\mu_{4}$ are represents four threshold to be estimated (along with the parameter vector $\beta$ ) that categorizes the observed variable $y$. The threshold values are corresponding to the cut-offs where an each categorical level changes from one category of QOS to another. Therefore, there are four thresholds to be estimated in case of six categories (Greene, Hensher 2010). The categorical data of y are related to the underlying variable of $y^{*}$ through threshold values $\mu$.

Therefore the probability that $y_{i}$ falling into the $j$-th category is given by:

$$
\begin{aligned}
& \operatorname{Prob}\left(y_{i}=j\right)=F\left(\mu_{j}-\beta X_{i}\right)-F\left(\mu_{j-1}-\beta X_{i}\right), \\
& j=1,2, \ldots, J,
\end{aligned}
$$

where: $\mu_{j}, \mu_{j-1}$ are the upper and lower threshold values for the category $J$.

The ordered probit model includes estimation of two sets of parameters. The constant and other threshold parameters specify the range of the normal distribution associated with specific values of the explanatory variables. The other important estimation is the marginal effect. The computation of marginal effect in the ordered probit model is important where the effect of variables $X$ on the intermediate category is ambiguous. These marginal effects indicate the relative importance of each variable in determining the likelihood to select the pedestrian QOS.

\section{Model Results}

Based on the 5216 data points (viz., 720 data points for model validation) with different behavioural characteristics of pedestrians' were considered to develop the pedestrian QOS model using NLOGIT 4.0 software package. For the ordered probit model, pedestrian QOS was considered as the dependent variable and coded as QOS $\mathrm{A}=0$ to $\mathrm{QOS} \mathrm{F}=5$ and other set of extracted data was considered as explanatory variables. The model results are presented in the Table 4 and significant variables corresponding to $95 \%$ significance confidence interval or higher are included in the model.

The goodness of fit of the model by $\rho^{2}$ is found as 0.11 . A positive value means that the explanatory variable increases the probability of pedestrian QOS F with an increase in its magnitude and that a negative value means that an increase in the variable gives a higher 
Table 4. Ordered probit model results of pedestrian QOS

\begin{tabular}{|l|c|c|c|c|}
\hline \multicolumn{1}{|c|}{ Variables } & $\begin{array}{c}\text { Estimated } \\
\text { coefficient, } \\
\beta\end{array}$ & $\begin{array}{c}\text { Standard } \\
\text { error }\end{array}$ & $t$-statistic & $p$-value \\
\hline Constant & 0.574 & 0.114 & 5.019 & 0.000 \\
\hline Land use type & 0.072 & 0.022 & 3.307 & 0.000 \\
\hline $\begin{array}{l}\text { Pedestrian } \\
\text { platoon size }\end{array}$ & -0.049 & 0.017 & -2.856 & 0.004 \\
\hline $\begin{array}{l}\text { Pedestrian } \\
\text { speed change } \\
\text { behaviour }\end{array}$ & 0.332 & 0.037 & 8.961 & 0.000 \\
\hline $\begin{array}{l}\text { Pedestrian } \\
\text { rolling } \\
\text { behaviour }\end{array}$ & 1.099 & 0.038 & 28.497 & 0.000 \\
\hline Vehicle speed & 0.007 & 0.002 & 3.578 & 0.003 \\
\hline Type of vehicle & -0.048 & 0.017 & -2.828 & $0.004^{*}$ \\
\hline $\begin{array}{l}\text { Driver yield } \\
\text { behaviour }\end{array}$ & 0.231 & 0.019 & 11.923 & 0.000 \\
\hline Type of gap & 0.076 & 0.027 & 2.731 & 0.006 \\
\hline Number of lanes & -0.188 & 0.015 & -12.674 & 0.000 \\
\hline $\begin{array}{l}\text { Presence of } \\
\text { zebra marking }\end{array}$ & 0.142 & 0.042 & 3.377 & $0.007^{*}$ \\
\hline $\begin{array}{l}\text { Number of } \\
\text { encountered } \\
\text { vehicles }\end{array}$ & 0.004 & 0.001 & 4.518 & 0.000 \\
\hline Threshold 1 $\left(\mu_{1}\right)$ & 1.159 & 0.021 & 54.938 & 0.000 \\
\hline Threshold 2 $\left(\mu_{2}\right)$ & 2.182 & 0.018 & 116.028 & 0.000 \\
\hline Threshold 3 $\left(\mu_{3}\right)$ & 3.276 & 0.023 & 140.450 & 0.000 \\
\hline Threshold $4\left(\mu_{4}\right)$ & 4.755 & 0.049 & 96.474 & 0.000 \\
\hline No. of samples & & 5216 & \\
\hline Log likelihood & & -6973.421 & \\
\hline $\begin{array}{l}\text { Restricted log } \\
\text { likelihood }\end{array}$ & & -7817.503 & \\
\hline Chi squared & & 1688.164 & \\
\hline $\begin{array}{l}\text { Degrees of } \\
\text { freedom }\end{array}$ & $\begin{array}{l}|c| \\
\text { ratio index }\left(\rho^{2}\right)\end{array}$ & & & \\
\hline Note: likelihood & & & & \\
\hline
\end{tabular}

Note: ${ }^{*}$ significance at $95 \%$ confidence interval. probability of QOS A. The marginal effects of each explanatory variable on each pedestrian QOS are reported in Table 5. A positive value indicates that an increase in the magnitude of the explanatory variable increases the probability of a specific QOS category.

\subsection{Model Validation}

The pedestrian QOS categories were developed based on the PCI (Table 3) and QOS model was developed as tabulated in Table 4. Further, the pedestrian QOS model was validated by using total 720 data points from two different locations (Andheri Parishwada and Malad unprotected mid-block crosswalk locations data, Table 1). Based on the model results significant variables were collected from the selected locations and QOS was derived based on PCI (observed QOS) and threshold values (Table 4). From the developed model (QOS based on model) the correct success prediction was observed as 0.67 as presented in Table 6 . The correct prediction was calculated as the sum of the diagonal values (482) divided with total number of observations (720) (Table 6). From the results, it can be noted that the model accounts for the pedestrian QOS quite well under mixed traffic conditions at unprotected mid-block crosswalk locations.

\section{Discussion}

The QOS of eight selected unprotected mid-block crosswalk locations along with average PCI index values are tabulated in Table 7 . It indicates the existing facilities at each selected location and also presents the various pedestrian crossing facilities required for a good crossing facility, but which are absent at these locations. The higher PCI index gives the lower QOS and the QOS can be improved by regulating pedestrian behaviour and vehicular speed by improving pedestrian safety with implementing traffic calming techniques as well as signboards (Table 7). Further, pedestrian safety may increase with providing barrier with sufficient grills (fences), see locations Borivali as well as Malad.

Table 5. Marginal effects of the pedestrian QOS

\begin{tabular}{|l|c|c|c|c|c|c|}
\hline \multirow{2}{*}{ Variable } & \multicolumn{9}{c|}{ Marginal Effects } \\
\cline { 2 - 8 } & $\begin{array}{c}Y=0 \\
\text { (QOS A) }\end{array}$ & $\begin{array}{c}Y=1 \\
\text { (QOS B) }\end{array}$ & $\begin{array}{c}Y=2 \\
\text { QOS C) }\end{array}$ & $\begin{array}{c}Y=3 \\
(\text { QOS D) }\end{array}$ & $\begin{array}{c}Y=4 \\
(\text { QOS E) }\end{array}$ & $\begin{array}{c}Y=5 \\
(\text { QOS F) }\end{array}$ \\
\hline Land use type & -0.002 & -0.014 & -0.012 & 0.012 & 0.015 & 0.001 \\
\hline PPS & 0.001 & 0.009 & 0.008 & -0.008 & -0.01 & -0.007 \\
\hline PSCB & -0.012 & -0.066 & -0.055 & 0.058 & 0.068 & 0.005 \\
\hline PRbeh & -0.039 & -0.217 & -0.182 & 0.194 & 0.228 & 0.017 \\
\hline Vehicle speed & -0.001 & -0.001 & -0.001 & 0.001 & 0.002 & 0.001 \\
\hline Type of vehicle & 0.002 & 0.009 & 0.008 & -0.008 & -0.011 & -0.001 \\
\hline DYB & -0.008 & -0.045 & -0.038 & 0.041 & 0.047 & 0.003 \\
\hline Type of gap & -0.003 & -0.015 & -0.012 & 0.013 & 0.015 & 0.001 \\
\hline Number of lanes & 0.006 & 0.037 & 0.031 & -0.033 & -0.039 & -0.003 \\
\hline PZM & -0.005 & -0.028 & -0.023 & 0.025 & 0.029 & 0.002 \\
\hline NOV & -0.001 & -0.001 & -0.001 & 0.001 & 0.001 & 0.001 \\
\hline
\end{tabular}

Notes: PPS - pedestrian platoon size; PSCB - pedestrian speed change behaviour; PRbeh - pedestrian rolling behaviour; DYB driver yield behaviour; PZM - presence of zebra marking; NOV - number of encountered vehicles. 
Table 6. QOS Model validation results

\begin{tabular}{|c|c|c|c|c|c|c|c|}
\hline Actual & $\begin{array}{c}Y=0 \\
(\mathrm{QOS} A)\end{array}$ & $\begin{array}{c}Y=1 \\
(\text { QOS B) }\end{array}$ & $\begin{array}{c}Y=2 \\
(\text { QOS C) }\end{array}$ & $\begin{array}{c}Y=3 \\
(\text { QOS D) }\end{array}$ & $\begin{array}{c}Y=4 \\
(\mathrm{QOS} E)\end{array}$ & $\begin{array}{c}Y=5 \\
\text { (QOS F) }\end{array}$ & Row sum \\
\hline $\begin{array}{c}Y=0 \\
(\mathrm{QOS} A)\end{array}$ & 64 & 2 & 1 & 0 & 0 & 0 & 67 \\
\hline $\begin{array}{c}Y=1 \\
(\text { QOS B) }\end{array}$ & 6 & 70 & 10 & 5 & 0 & 0 & 91 \\
\hline $\begin{array}{c}Y=2 \\
(\mathrm{QOS} C)\end{array}$ & 18 & 22 & 82 & 16 & 4 & 2 & 144 \\
\hline $\begin{array}{c}Y=3 \\
(\text { QOS D) }\end{array}$ & 8 & 11 & 9 & 75 & 26 & 14 & 143 \\
\hline $\begin{array}{c}Y=4 \\
(\mathrm{QOS} E)\end{array}$ & 4 & 6 & 14 & 11 & 89 & 15 & 139 \\
\hline $\begin{array}{c}Y=5 \\
(\mathrm{QOS} F)\end{array}$ & 0 & 0 & 0 & 6 & 28 & 102 & 136 \\
\hline Column sum & 100 & 111 & 116 & 113 & 147 & 133 & 720 \\
\hline
\end{tabular}

Table 7. Selected Unprotected Crosswalks PCI and QOS

\begin{tabular}{|l|c|c|c|c|c|c|c|c|c|}
\hline \multirow{2}{*}{$\begin{array}{c}\text { Location } \\
\text { name }\end{array}$} & \multirow{2}{*}{ PCI } & \multirow{2}{*}{ QOS } & \multirow{2}{*}{ PSM } & \multicolumn{7}{|c|}{ Existing facilities } \\
\cline { 5 - 10 } & & & & ZMC & WOM & MWG & MOW & SBC & TCM \\
\hline Ghatkopar & 4.0 & $\mathrm{D}$ & 1.85 & $\times$ & $\times$ & $\times$ & $\times$ & $\times$ & $\times$ \\
\hline Borivali & 3.5 & $\mathrm{C}$ & 3.02 & $\times$ & 0.7 & $\checkmark$ & 3.0 & $\times$ & $\times$ \\
\hline $\begin{array}{l}\text { Andheri } \\
\text { Parsiwada }\end{array}$ & 3.6 & $\mathrm{D}$ & 2.92 & $\checkmark$ & 0.45 & $\times$ & $\times$ & $\times$ & $\times$ \\
\hline Kurla & 3.6 & $\mathrm{D}$ & 2.78 & $\times$ & 1.0 & $\times$ & 3.0 & $\times$ & $\times$ \\
\hline Lower Parel & 3.6 & $\mathrm{D}$ & 2.85 & $\checkmark$ & 1.0 & $\times$ & 3.0 & $\times$ & $\times$ \\
\hline Malad & 3.3 & $\mathrm{C}$ & 3.17 & $\times$ & 0.7 & $\checkmark$ & 3.5 & $\times$ & $\times$ \\
\hline Prabhadevi & 3.2 & $\mathrm{C}$ & 3.56 & $\checkmark$ & 1.25 & $\times$ & 5.0 & $\times$ & $\times$ \\
\hline Chembur & 3.3 & $\mathrm{C}$ & 3.24 & $\times$ & 1.0 & $\times$ & 3.5 & $\times$ & $\times$ \\
\hline
\end{tabular}

Notes: PCI - pedestrian crossing index; QOS - quality of service; PSM - pedestrian safety margin [s]; ZMC - zebra marking condition; WOM -width of median (barrier) [m]; MWG - median with sufficient grills to control pedestrian illegal crossings; MOW - median opening width [m]; SBC - sign board condition; TCM - traffic calming measurements (pedestrian speed tables, curb extension, highlighting crosswalks with special lighting condition, etc.).

However, the QOS of selected locations were either C or below, which clearly shows overall below par crossing facilities at selected crosswalk locations. The PCI of these locations may decreases with implementation of non-availability of these facilities (Table 7) and further it helps in improving the pedestrian safety. The developed model for assessment of QOS of mid-block crosswalks may be also useful for choosing the crosswalk location from available alternatives, based on values of PCI, which is an indicator of QOS. Further, higher values of PCI may also indicate need for improvement in pedestrian crossing facilities at the crosswalks. The authors believe that more studies at different crosswalks in other cities in developing countries would help in suggesting generalized guidelines based on the developed model, for new crosswalk planning and up-gradation of existing crosswalks.

The study also found that the adjacent land use type (viz., residential areas, commercial shopping complex, hospitals, banks, etc.) near the unprotected mid-block crosswalk has significant effect on the pedestrian QOS.
Further, it is found that the crosswalks at the shopping area has lower QOS than at the other land use types such as mixed and residential type. It may be due to the lower safety margins at shopping areas than the other land use types due to higher roadside parking. Previous research studies also shows that the retail as well as residential land use types have higher pedestrian casualties than the mix dense land use and intensity of land use has significant effect on traffic designs as well as accessibility (Meurs, Van Wee 2003; Wedagama et al. 2006; Dissanayake et al. 2009; Iravani et al. 2011). Research studies also show that the land use type has significant contribution on pedestrian perceived LOS (Kadali, Vedagiri 2015). Pedestrian may use behavioural characteristics such as change in speed and rolling behaviour to reduce the delay by accepting available inadequate gaps under a mixed traffic condition at unprotected mid-block location. Pedestrian may reduce delay but the interaction with vehicular flow increases and it may reduce the safety of pedestrian in such a situation. Overall, with the reduction in gap size as well as safety margin, PCI value 
may increase and increase in PCI leads to decrease in pedestrian QOS towards QOS F.

Moreover, the vehicular characteristics have a significant effect on pedestrian QOS. Pedestrian have more interaction with smaller vehicle types such as twowheeler and three-wheeler (auto rickshaw) because of rolling behaviour and pedestrian may maintain higher safety margin values with heavy vehicles. Therefore, an increase in vehicle size leads to pedestrian have higher QOS category towards QOS A. In addition, the probability that two-wheelers and three-wheeler may yield to pedestrian is higher than the heavy vehicles such as truck and bus drivers. Therefore, the increase in driver yield behaviour also leads to reduction in the accepted vehicular gap by pedestrian further increasing the interaction with vehicles. Further, driver yield behaviour also leads to pedestrian lower QOS categories. The increase in vehicular speed has significant effect on reduction of pedestrian safety at unprotected mid-block crosswalk locations. Therefore, there is a decrease in pedestrian QOS category. The increase in number of vehicle encountered by pedestrian decreases the pedestrian QOS towards LOS F and it may be due to the increasing waiting time (it is observed that the waiting time increases to $178 \mathrm{~s}$ with 230 vehicles-pedestrian interaction during that time at Chembur site) as well as decrease in safety because of pedestrian attempting inadequate vehicular gaps after long waiting time.

The roadway characteristics have also been identified as an important contributing parameter in pedestrian QOS. In this study, it is found that with the decrease in a number of lanes (at lower vehicle lanes) there is an increase in pedestrian QOS towards LOS F. This is because, the pedestrian exhibit behavioural characteristics (using rolling behaviour or increase in speed) more at two-way and four way roadway locations than the six lane divided roadway location. It is worth noting that in case of developing countries, there is a greater interaction of pedestrians with vehicles at locations with less number of lanes (sub-arterials, etc.) and it leads to lot of discomfort to pedestrians (while crossing the road) as well as to the vehicle drivers. In addition, it is observed that the pedestrian are maintaining higher safety margin values while crossing six lanes divided roadway than the other types of roadway, and this increase in safety margin value indicates the decrease in PCI value and overall pedestrian QOS shifts towards higher category, viz., QOS A for six-lane roadway.

The study result also show that zebra marked crosswalks have lower category of QOS than the nonzebra crosswalk locations because of the increase in pedestrian-vehicle interaction at zebra crosswalk locations due to ambiguity of driver yield behaviour. Early research studies found that marked crosswalks have lower safety than the non-marked crosswalk locations at uncontrolled crosswalk locations (Zegeer et al. 2001; Mitman, Ragland 2007). The driver yield behaviour under mixed traffic conditions in developing countries is quite different when compared with developed countries and it is noticed only when the pedestrians are using the crosswalks or when the pedestrians already reached the vehicular lanes (Kadali, Vedagiri 2013). Further, the driver yield behaviour has also been observed in nonzebra marked locations when the pedestrians are using crosswalks or when they are already in crosswalk locations. However, this driver yield behaviour is observed to be slightly higher at zebra marked crosswalk locations than the non-marked crosswalks. So, further studies are required to conclude the effect of zebra crossing on QOS along with driver yield behaviour under mixed traffic conditions.

The increase or decrease in probability of each category of pedestrian QOS with each explanatory variable can be explained by the marginal effect. The marginal effects (Table 5) show that land use type has influence on pedestrian QOS, as the probability of lower QOS D increases by $1.2 \%$ with an increase in shopping area as land use type, QOS E increases by 1.5\%, QOS F increases by $0.1 \%$, whereas the probability of QOS C decreases by $1.2 \%$, QOS B decreases by $1.4 \%$, and QOS A decrease by $0.2 \%$. It is also interpreted that increase in pedestrian speed change behaviour will result in an increase the probability of QOS D by $5.8 \%$, QOS E by $6.8 \%$ and QOS F by $0.5 \%$, whereas, the probability of higher QOS category such as QOS A, QOS B and QOS C decrease by $1.2,6.6$ and $5.5 \%$ respectively.

It is observed that from the marginal effect results (Table 5), the usage of behavioural characteristics such as rolling as well as speed change behaviour by pedestrian results in a significant reduction in the probability of higher QOS categories (QOS A, etc.) and increase in the probability of lower QOS categories D to $\mathrm{F}$. The vehicle speed also has significant effect and results in increase in probability of lower category towards QOS F. However, with the increase in vehicle size (heavy vehicles) there is an increase in the probability of QOS A by $0.2 \%$, QOS B by $0.9 \%$ and QOS C by $0.8 \%$ and decrease in probability of lower category QOS D by $0.8 \%$, QOS E by $1.1 \%$ and QOS F by $0.1 \%$. From the Table 5 , it is also observed that with the decrease in a number of lanes, there is an increase in probability of higher pedestrian QOS towards QOS A. With respect to the traffic characteristics such as type of gap, it is observed that with an increase in acceptance of far gaps, there is an increase in pedestrian QOS E or F. This is due to decrease in pedestrian safety with far gaps as compared to near gaps. The roadway characteristics (viz., number of lanes) have significant contribution towards pedestrian QOS and it increases the QOS towards higher categories (Table 5) at unprotected mid-block crosswalk locations. The number of vehicles encountered by the pedestrians while crossing the road increases their road crossing difficulty and it increases the discomfort levels of pedestrians (Chu, Baltes 2003; Kadali, Vedagiri 2015). Therefore, the traffic volume has significant contribution in designing of pedestrian crosswalk facilities and increase in the traffic volume shows an increase in use of pedestrian behavioural characteristics for road crossing. 
Further, the study results revealed that with the increase in encountered vehicles while crossing the road, there is an increase in the probability of pedestrian QOS towards F (Table 5).

From the study results, it can be noted that there is a significant effect of pedestrian behavioural characteristics on pedestrian QOS and with an increase in use of such behavioural characteristics pedestrian QOS decreases. The developed QOS index values based on the PCI is close to the developed model threshold values (Tables 3-4). Further, the developed QOS model may be quite useful to capture the pedestrian QOS with pedestrian behavioural and vehicular characteristics along with different roadway characteristics at unprotected mid-block crosswalk locations under mixed traffic conditions.

\section{Conclusions}

The present study derived pedestrian QOS based on the PCI values. The pedestrian safety margin, crossing opportunities and delay values were used to define the PCI. From the results, it is concluded that the single performance measure of pedestrian delay is not effective to assess the pedestrian QOS at unprotected midblock crosswalk locations under mixed traffic condition. Therefore, the study results suggested the importance of pedestrian safety and available adequate gaps along with delay in pedestrian crosswalk service evaluation. Further, the ordered probit model was used to examine the contributing variables on pedestrian QOS at unprotected mid-block crosswalk locations under mixed traffic condition. From the results, it can be concluded that pedestrian behavioural characteristics (rolling and speed change behaviour) significantly reduces the pedestrian QOS. It can be concluded that pedestrian QOS reduces with higher vehicle speed and smaller vehicle size (two and three wheeler). Further, it is also observed that pedestrians have higher QOS at six-lane roadway as compared to the four as well as two-lane roadway. The pedestrian behavioural characteristics are more visible at two and four lane than the six-lane roadway. It is also observed that the pedestrian QOS reduces while accepting far gaps rather than the near gaps. It is found that the increase in number of encountered vehicles by pedestrian decreases the pedestrian QOS.

This study has some limitations, the pedestrian comfort and convenience have not been considered directly for assessing pedestrian QOS. However, comfort and convenience are considered indirectly with pedestrian gap index value of pedestrian crossing opportunities. The present study is also limited to the unprotected mid-block crosswalk locations. Further, the study could not consider the effect of lighting facilities, weather, visibility, sign board, pedestrian trip purpose and pedestrian perception on pedestrian QOS at midblock crosswalk locations, as the survey was conducted at each selected locations in normal weather, day light (visibility is good). While, some of these factors have been extensively studied at both signalized crosswalk locations, further study is required to study the effect of above mentioned parameters on pedestrian QOS at unprotected mid-block crosswalk locations. In spite of these limitations, the study contributes by developing a method to evaluate the pedestrian QOS by pedestrian safety, crossing opportunities and delay factors at unprotected mid-block crosswalk locations under mixed traffic conditions. The study also identifies the important factors, which contribute towards the pedestrian QOS at unprotected mid-block crosswalk locations under mixed traffic condition. These results are important for rating the existing crosswalk locations under mixed traffic conditions based on PCI and for suggesting improvement measures to improve the quality of crosswalk facilities. Further, these results may also be useful for suggesting the guidelines in designing of new crosswalk facility and for providing measures to control the pedestrian behavioural characteristics at unprotected mid-block location to improve safety as well as pedestrian QOS.

\section{Acknowledgements}

The authors are thankful to the Mr. Rajesh and Ms. Santhoshi who provided help in the data collection, questionnaire survey and filled in our questionnaire. The authors are also grateful to the two anonymous reviewers for their valuable comments and suggestions on the earlier version of this manuscript, which helped the authors significantly, improve the manuscript.

\section{References}

Baltes, M. R.; Chu, X. 2002. Pedestrian level of service for midblock street crossings, Transportation Research Record: Journal of the Transportation Research Board 1818: 125133. http://doi.org/10.3141/1818-19

Bian, Y.; Jian, L.; Zhao, L. 2013. Method to determine pedestrians level of service for unsignalized intersections, Applied Mechanics and Materials 253-255: 1936-1943.

http://doi.org/10.4028/www.scientific.net/AMM.253-255.1936

Brewer, M. A.; Fitzpatrick, K.; Whitacre, J.; Lord, D. 2006. Exploration of pedestrian gap-acceptance behavior at selected locations, Transportation Research Record: Journal of the Transportation Research Board 1982: 132-140.

http://doi.org/10.3141/1982-18

Chang, K. 2004. Multiattribute Weighting Models for Best-Value Selection in Public Sector Design-Build Projects: PhD Thesis. University of Colorado Boulder, United States. 267 p.

Chu, X.; Baltes, M. 2003. Measuring pedestrian quality of service for midblock street crossings: selection of potential determinants, Transportation Research Record: Journal of the Transportation Research Board 1828: 89-97. http://doi.org/10.3141/1828-11

Diogenes, M.; Lindau, L. 2010. Evaluation of pedestrian safety at midblock crossings, Porto Alegre, Brazil, Transportation Research Record: Journal of the Transportation Research Board 2193: 37-43. http://doi.org/10.3141/2193-05

Dissanayake, D.; Aryaija, J.; Wedagama, D. M. P. 2009. Modelling the effects of land use and temporal factors on child pedestrian casualties, Accident Analysis \& Prevention 41(5): 1016-1024. http://doi.org/10.1016/j.aap.2009.06.015 
Faria, J.; Krause, S.; Krause, J. 2010. Collective behavior in road crossing pedestrians: the role of social information, Behavioral Ecology 21(6): 1236-1242.

http://doi.org/10.1093/beheco/arq141

Gårder, P. E. 2004. The impact of speed and other variables on pedestrian safety in Maine, Accident Analysis \& Prevention 36(4): 533-542.

http://doi.org/10.1016/S0001-4575(03)00059-9

Greene, W. H.; Hensher, D. A. 2010. Modeling Ordered Choices: a Primer. Cambridge University Press. 382 p.

Hamed, M. M. 2001. Analysis of pedestrians' behavior at pedestrian crossings, Safety Science 38(1): 63-82. http://doi.org/10.1016/S0925-7535(00)00058-8

Harkey, D. L.; Reinfurt, D. W.; Knuiman, M.; Stewart, J. R.; Sorton, A. 1998. Development of the Bicycle Compatibility Index: a Level of Service Concept. Final Report No. FHWARD-98-072. US Department of Transportation, Federal Highway Administration. 116 p. Available from Internet: http://safety.fhwa.dot.gov/tools/docs/bcifinalrpt.pdf

Hauer, E.; Garder, P. 1986. Research into the validity of the traffic conflicts technique, Accident Analysis \& Prevention 18(6): 471-481.

http://doi.org/10.1016/0001-4575(86)90020-5

Havard, C.; Willis, A. 2012. Effects of installing a marked crosswalk on road crossing behaviour and perceptions of the environment, Transportation Research Part F: Traffic Psychology and Behaviour 15(3): 249-260. http://doi.org/10.1016/j.trf.2011.12.007

Highway Capacity Manual. 2010. Transportation Research Board. 5th edition. $1650 \mathrm{p}$.

Iravani, H.; Mirhoseini, A.; Rasoolzadeh. M. 2011. Defining land use intensity based on roadway level of service targets, Journal of Transport and Land Use 4(1): 59-69.

Ishaque, M. M.; Noland, R. B. 2008. Behavioural issues in pedestrian speed choice and street crossing behaviour: a review, Transport Reviews 28(1): 61-85. http://doi.org/10.1080/01441640701365239

Jain, A.; Gupta, A.; Rastogi, R. 2014. Pedestrian crossing behaviour analysis at intersections, International Journal for Traffic and Transport Engineering 4(1): 103-116. http://doi.org/10.7708/ijtte.2014.4(1).08

Jensen, S. U. 2013. Pedestrian and bicycle level of service at intersections, roundabouts, and other crossings, in TRB 92nd Annual Meeting Compendium of Papers, 13-17 January 2013, Washington, DC, 1-19.

Kadali, B. R.; Vedagiri, P. 2015. Evaluation of pedestrian crosswalk level of service (LOS) in perspective of type of landuse, Transportation Research Part A: Policy and Practice 73: 113-124. http://doi.org/10.1016/j.tra.2015.01.009

Kadali, B. R.; Vedagiri, P. 2013. Modelling pedestrian road crossing behaviour under mixed traffic condition, European Transport - Trasporti Europei 55(3): 1-17.

Khattak, A. J.; Koppelman, F. S.; Schofer, J. L. 1993. Stated preferences for investigating commuters' diversion propensity, Transportation 20(2): 107-127. http://doi.org/10.1007/BF01307055

Khisty, C. J. 1994. Evaluation of pedestrian facilities: beyond the level-of-service concept, Transportation Research Record: Journal of the Transportation Research Board 1438: $45-50$.

Knoblauch, R. L.; Nitzburg, M.; Seifert, R. F. 2001. Pedestrian Crosswalk Case Studies: Richmond, Virginia; Buffalo, New York; Stillwater, Minnesota. Report No. FHWA-RD-00-103. US Department of Transportation, Federal Highway Ad- ministration. 52 p. Available from Internet: http://www. fhwa.dot.gov/publications/research/safety/00103/00103.pdf

Lasmini, A.; Indriastuti, A. K. 2010. Optimization of safe pedestrian facilities and traffic management, a case study of Malang, Indonesia, Journal of Economics and Engineering 1(4): 8-14.

Leather, J.; Fabian, H.; Gota, S.; Mejia, A. 2011. Walkability and Pedestrian Facilities in Asian Cities: State and Issues. ADB Sustainable Development Working Paper Series. Asian Development Bank, Manila, Philippines. 78 p. Available from Internet: http://www.adb.org/sites/default/files/publication/28679/adb-wp17-walkability-pedestrian-facilitiesasian-cities.pdf

Lobjois, R.; Cavallo, V. 2009. The effects of aging on streetcrossing behavior: from estimation to actual crossing, Accident Analysis \& Prevention 41(2): 259-267.

http://doi.org/10.1016/j.aap.2008.12.001

Meurs, H.; Van Wee, B. 2003. Land use and mobility: a synthesis of findings and policy implications, European Journal of Transport and Infrastructure Research 3(2): 219-233.

Milazzo J.; Rouphail, N.; Hummer, J.; Allen, D. 1999. Quality of service for interrupted-flow pedestrian facilities in Highway Capacity Manual 2000, Transportation Research Record: Journal of the Transportation Research Board 1678: 25-31. http://doi.org/10.3141/1678-04

Mitman, M.; Ragland, D. 2007. Crosswalk confusion: more evidence why pedestrian and driver knowledge of the vehicle code should not be assumed, Transportation Research Record: Journal of the Transportation Research Board 2002: 55-63. http://doi.org/10.3141/2002-07

Mohan, D.; Tsimhoni, O.; Sivak, M.; Flannagan, M. J. 2009. Road safety in India: Challenges and Opportunities. Transport Research Institute, University of Michigan. 62 p. Available from Internet: https://deepblue.lib.umich.edu/ handle/2027.42/61504

Nagraj, R.; Vedagiri, P. 2013. Modeling pedestrian delay and level of service at signalized intersection crosswalks under mixed traffic conditions, Transportation Research Record: Journal of the Transportation Research Board 2394: 70-76. http://doi.org/10.3141/2394-09

Petritsch, T.; Landis, B.; McLeod, P.; Huang, H.; Challa, S.; Guttenplan, M. 2005. Pedestrians: level-of-service model for pedestrians at signalized intersections, Transportation Research Record: Journal of the Transportation Research Board 1939: 53-62. http://doi.org/10.3141/1939-07

Ponnaluri, R. V. 2012. Road traffic crashes and risk groups in India: analysis, interpretations, and prevention strategies, IATSS Research 35(2): 104-110. http://doi.org/10.1016/j.iatssr.2011.09.002

Sarkar, S. 1993. Determination of service levels for pedestrians, with European examples, Transportation Research Record: Journal of the Transportation Research Board 1405: 35-42.

Sun, D.; Ukkusuri, S. V. S. K.; Benekohal, R. F.; Waller, S. T. 2003. Modeling of motorist-pedestrian interaction at uncontrolled mid-block crosswalks, in TRB 82nd Annual Meeting Compendium of Papers, 12-16 January 2003, Washington, DC, 1-34.

Tulu, G. S.; Washington, S.; King, M. J.; Haque, M. M. 2013. Why are pedestrian crashes so different in developing countries? A review of relevant factors in relation to their impact in Ethiopia, in 36th Australasian Transport Research Forum (ATRF): Transport and the New World City, 2-4 October 2013, QUT Gardens Point, Brisbane, Australia, 1-18. Available from Internet: http://eprints.qut.edu.au/63789 
Washington, S. P.; Karlaftis, M. G.; Mannering, F. 2010. Statistical and Econometric Methods for Transportation Data Analysis. 2nd edition. Chapman and Hall/CRC. 544 p.

Wedagama, D. M. P.; Bird, R. N.; Metcalfe, A. V. 2006. The influence of urban land-use on non-motorised transport casualties, Accident Analysis \& Prevention 38(6): 1049-1057. http://doi.org/10.1016/j.aap.2006.01.006

Yannis, G.; Papadimitriou, E.; Theofilatos, A. 2013. Pedestrian gap acceptance for mid-block street crossing, Transportation Planning and Technology 36(5): 450-462. http://doi.org/10.1080/03081060.2013.818274

Zegeer, C.; Stewart, J.; Huang, H.; Lagerwey, P. 2001. Safety effects of marked versus unmarked crosswalks at uncontrolled locations: analysis of pedestrian crashes in 30 cities, Transportation Research Record: Journal of the Transportation Research Board 1773: 56-68.

http://doi.org/10.3141/1773-07 